\title{
Microencapsulation with Maillard Reaction Products to improve the oxidative stability of chia oil
}

\section{Claudia N. Copado, Bernd W.K. Diehl, Vanesa Y. Ixtaina, and Mabel C. Tomás}

- Chia seed oil is rich in omega-3

polyunsaturated fatty acids

( 60\%), which makes it an

interesting source for enriching

foods with these essential fatty

acids.

- The high susceptibility of chia

oil to lipid oxidation makes it

challenging to include this oil

as an ingredient in different

foods.

- Our research showed that

encapsulating chia seed oil in

microcapsules produced by

spray-drying with Maillard

Reaction Products improves

the oil's oxidative stability.
The oil obtained from the seeds of chia (Salvia hispanica L.) is a valuable plant source of omega-3 polyunsaturated fatty acids (PUFA). Chia oil's high PUFA content makes it an interesting source for enriching foods with these essential fatty acids, but the oil's high PUFA content also makes it susceptible to oxidation. Consequently, one of the most relevant challenges is to protect the oil from oxidative deterioration.

Recently, different studies have demonstrated that microencapsulation confers chia oil with protection against this type of deterioration [1-5]. Moreover, the oxidative stability of chia oil can be further improved through other strategies, such as using compounds with antioxidant properties. Toward this end, the Maillard Reaction Products (MRPs) formed during the classic chemical reaction between amino acids and reducing sugars are a good encapsulant system for oils with high PUFA contents [6] since these protein-carbohydrate conjugates possess emulsifying and antioxidant properties. Although questions about possible toxic effects of MPRs have been raised, some studies have reported that these products are not likely to be dietary mutagens or genotoxic, and some MRPs even have health-promoting effects [6].

Our research work has focused on generating MRPs from different heat treatments of sodium caseinate ( $\mathrm{NaCas})(10 \% \mathrm{wt} / \mathrm{wt})$ and lactose $(10 \% \mathrm{wt} / \mathrm{wt})$, then applying these MRPs as wall material in the microencapsulation of chia oil by spray drying.

To promote NaCas-lactose conjugates production through the Maillard Reaction, we applied two different heat treatments $\left(60\right.$ or $100^{\circ} \mathrm{C}, 30 \mathrm{~min}$ ) to the protein-carbohydrate mixture, with an unheated mixture of $\mathrm{NaCas-lactose} \mathrm{mix-}$ ture serving as a control. The absorbance, measured using a spectrophotometer at a wavelength of $465 \mathrm{~nm}$, and the color of the aqueous phase indicated that heating the mixture to $100^{\circ} \mathrm{C}$ produced the most browning, which is associated with the formation of MRPs called melanoidins. Also, Fourier-transform infrared spectroscopy (FTIR) spectrums showed that the most intense heat treatment promoted MRPs to a greater extent than lower or no heat treatment did. A DPPH (2,2-diphe- 


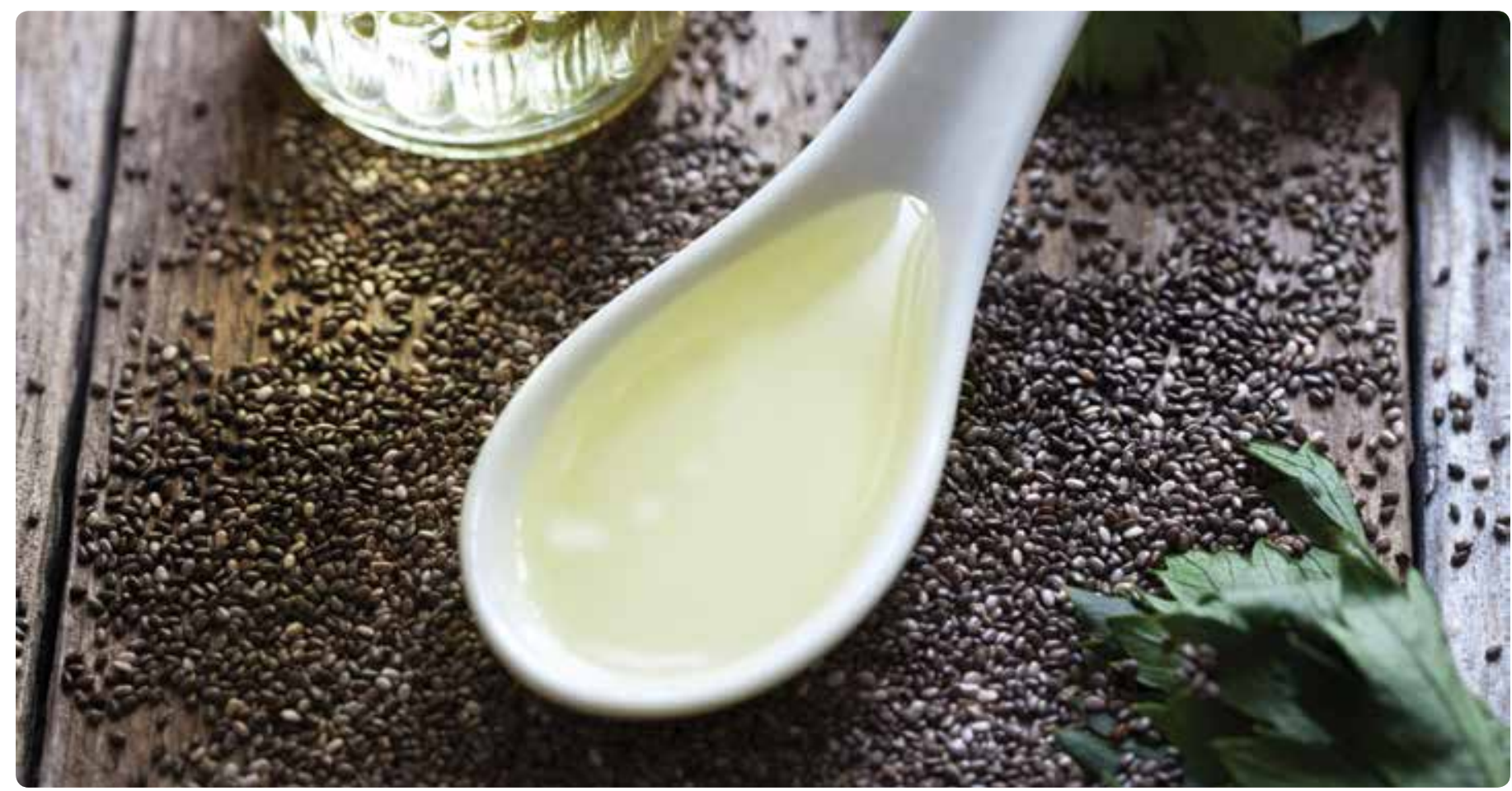

nyl-1-picryl-hydrazyl-hydrate) antioxidant assay provided further evidence that the aqueous phase constituted by the $\mathrm{NaCas}$-lactose mixture treated at $100^{\circ} \mathrm{C}$ presented the highest antioxidant activity ( $\left(\mathrm{C}_{50} 18.14\right.$ microliters).

From these aqueous phases, oil-in-water emulsions were prepared with $10 \% \mathrm{wt} / \mathrm{wt}$ of chia seed oil, using a pre-emulsification step followed by homogenization at high pressure. This process allowed us to obtain monomodal emulsions with $\mathrm{D}[3,2]$ particle sizes of $\sim 0.25$ micrometer and high physical stability-essential characteristics for achieving a high microencapsulation efficiency. For this to occur, the oil droplets must be entirely covered by the wall material to form a crust around the core when the emulsion is dehydrated. Although all the parent emulsions presented good characteristics, those sub- jected to the highest temperature had the smallest particle size and narrowest size distributions-characteristics related to these systems having the highest amount of MRPs with good emulsifying properties [6].

Microencapsulated chia seed oil was produced by spray-drying the emulsions at $170 / 90^{\circ} \mathrm{C}$ of air inlet/outlet temperatures on a laboratory-scale equipment. Figure 1 summarizes the process of microcapsules production.

Measurements of microencapsulation efficiency (ME\%) (ME\%=surface oil/total oilx100), moisture content, and $a_{\mathrm{w}}$ were performed immediately after powder production. The results showed high microencapsulation efficiency ( 99\%), with moisture content and water activities $\left(a_{\mathrm{w} 255^{\circ}}\right)$ in the range of $0.02-3.00 \%$ (d.b.) and 0.243-0.470, respectively. Thus, the

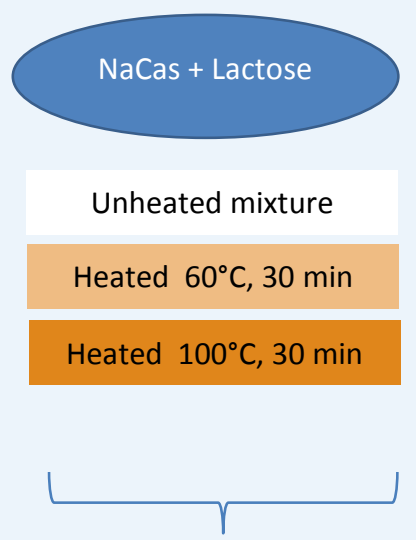

Aqueous phases

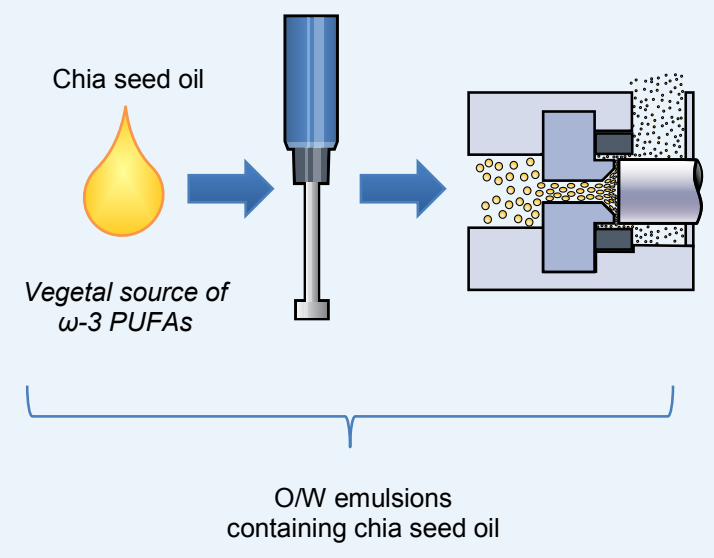

Microencapsulated chia seed oil 


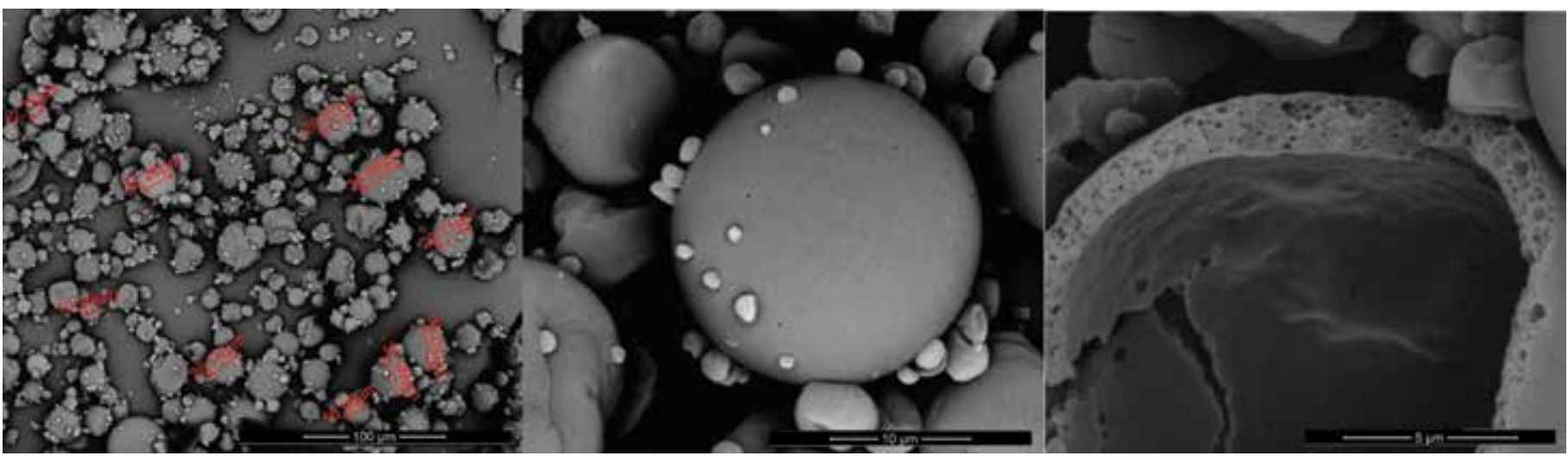

FIG. 2. Scanning electron microscopy (SEM) image of spray-dried microcapsules containing chia seed oil with MRPs as wall material

resulting microcapsules from this process presented an oil load of 33\% wt/wt, with a 1:2 core:wall ratio. The low levels of moisture content and $\mathrm{a}_{\mathrm{w} 25^{\circ} \mathrm{C}}$ are adequate for incorporating these powders into different dried powdered foods. With this in mind, we investigated the dispersibility of the powders
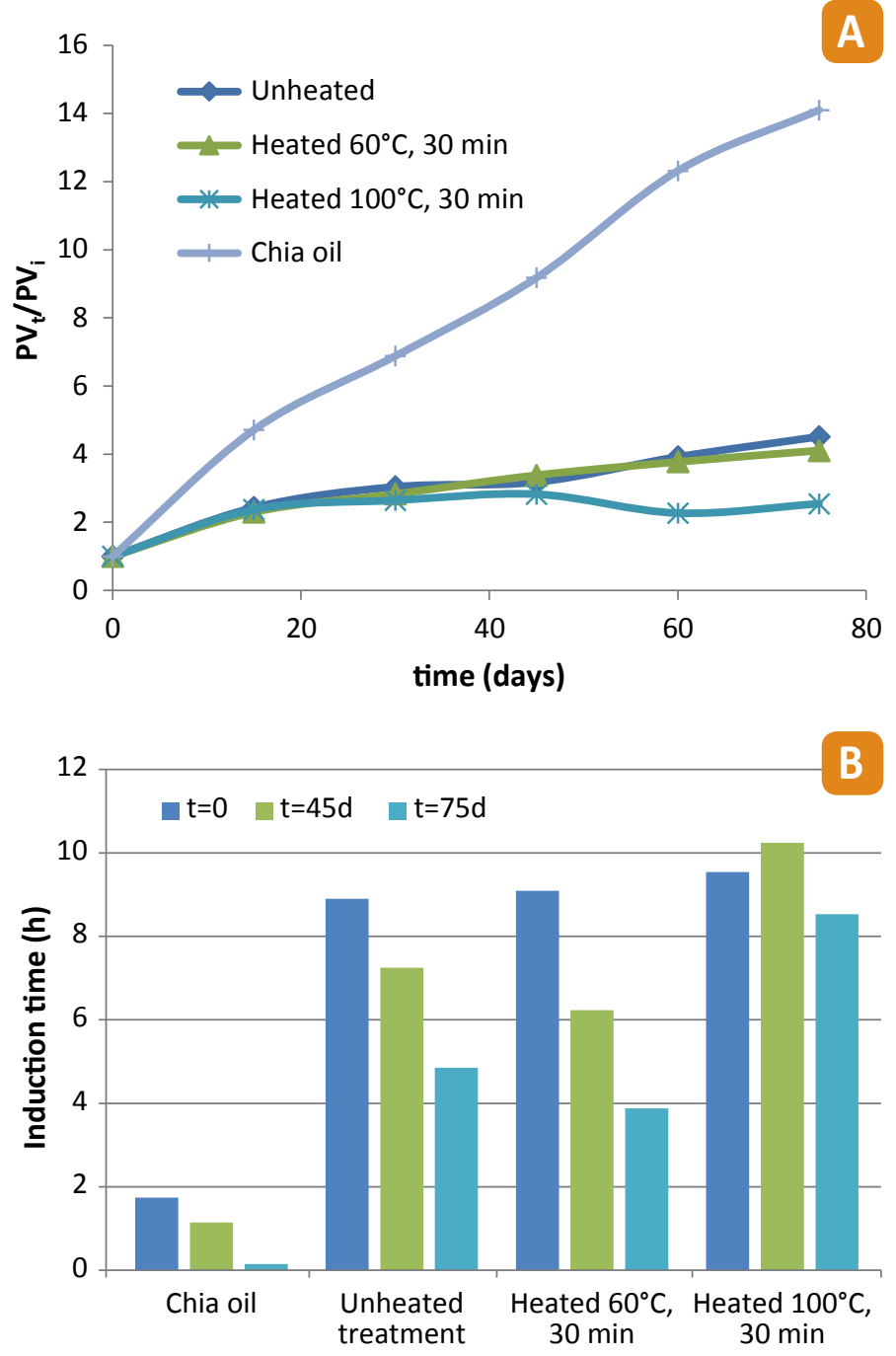

FIG. 3. Evolution of (a) the peroxide value (PV) and (b) the induction time (Rancimat test) of bulk and microencapsulated chia seed oil during storage for $75 \mathrm{~d}$ at $25 \pm 2^{\circ} \mathrm{C}, 33 \% \mathrm{RH}$, and darkness using a laser diffraction instrument. After adding a portion of the samples ( $0.3 \mathrm{mg}$ of powder $/ \mathrm{mL}$ ) to the stirring chamber containing distilled water, the obscuration and the particle size were monitored as a function of stirring time. The rapid powder dispersibility (<2min) suggested that the microcapsules could be suitable for use in instant products.

Figure 2 shows the scanning electron microscopy (SEM) images of the obtained microcapsules at different magnifications. Regardless of the treatment, most of the particles had sizes between 10 and 35 micrometers, a spherical shape, and smooth external surfaces. With respect to the internal structure, we observed the presence of a hollow space in the center of the particles. This space is surrounded by the dry solid matrix, with the core material distributed inside of it. This cavity was likely due to the expansion of the microcapsules in the latest stage of the drying process. [7].

In terms of oxidative stability, all the microencapsulated systems had a protective effect on the chia oil (Fig. 3). At $t=0$ $\mathrm{d}$, the peroxide value (PV) of chia oil was $2.6 \mathrm{meq} / \mathrm{kg}$, whereas the PVs of the microencapsulated oils were $3.9,3.5$, and 5.0 $\mathrm{meq} / \mathrm{kg}$ for the unheated, and the 60 and $100^{\circ} \mathrm{C}$-heated treatments, respectively. Although the microencapsulation process slightly affected the initial oxidation status of chia oil, all treatments resulted in PVs lower than the upper limit recommended by the Codex Alimentarius for this type of oil $(<10$ $\mathrm{meq} / \mathrm{kg}$ ).

The evolution of PV in the bulk oil and the microcapsules during 75 days of storage in the dark at $25 \pm 2{ }^{\circ} \mathrm{C}$ and $33 \%$ relative humidity was also investigated. Figure 3 a shows the evolution of the $\mathrm{PV}_{\mathrm{t}} / \mathrm{PV}_{\mathrm{i}}$ index, with $\mathrm{PV}_{\mathrm{t}}$ being the value at different storage times, and $\mathrm{PV}_{\mathrm{i}}$ the value corresponding to the initial time. The PV of the bulk chia oil increased 14 times during 75 days of storage, while the PV levels of the microencapsulated systems only doubled or quadrupled. Microcapsules obtained from emulsions constituted by the aqueous phase submitted to heat treatment of $100^{\circ} \mathrm{C}, 30 \mathrm{~min}$ had the lowest PV level. The inverse relationship observed between the MRP and PV values suggests that the protection of chia oil against lipid oxidation during storage was higher when the most intense heat treatment was applied. Thus, the MRPs generated with the treatment at $60^{\circ} \mathrm{C}, 30 \mathrm{~min}$ was not enough to confer additional protection to the microencapsulated oil. 
Conversely, MRPs generated with treatment at $100^{\circ} \mathrm{C}, 30$ min increased the stability of the microencapsulated oil, allowing it to maintain a PV $<10 \mathrm{meq} / \mathrm{kg}$ after 75 days of storage. The accelerated oxidation test, measured by Rancimat equipment $\left(98^{\circ} \mathrm{C}, 20 \mathrm{~L} / \mathrm{h}\right)$, was consistent with the PV measurements (Fig. 3b). The induction times of the microencapsulated oils, which were four times higher than the induction time of the bulk chia oil, showed that the microencapsulation process protected the chia oil from lipid oxidation in all cases. Although the oxidation status of the microencapsulated systems did not differ significantly at the beginning of the storage test, the microcapsules prepared with the aqueous phase treated at $100^{\circ} \mathrm{C}, 30 \mathrm{~min}$ had the highest induction time at the end of the test. No significant differences in the omega- 3 content of the microencapsulated oils were observed between the initial and the final storage time.

Thus, applying MRPs as wall material improves the oxidative stability of spray-dried microencapsulated chia seed oil and appears to be a viable alternative for delivering and applying this oil in the production of omega-3 fortified foods. Additional studies are necessary to investigate other temperature-time combinations that could promote higher quantities of MRPs and have a greater impact on the oxidative status of chia oil and the characteristics of the microcapsules.

Claudia N. Copado studied Food Engineering at the Universidad Nacional de Cuyo (UNCuyo), Argentina, and is now a Ph.D. student at the Facultad de Ciencias Exactas, UNLP, Argentina. She has received a doctoral fellowship from the Consejo Nacional de Investigaciones Cientificas y Técnicas (CONICET), Argentina, and conducts her research activities at Centro de Investigación y Desarrollo en Criotecnología de Alimentos-CIDCA (CONICET-CIC-UNLP).

Bernd W.K. Diehl obtained his Ph.D. at Philipps University Marburg, Germany, in 1988. Diehl is founder and CEO of Spectral Service GmbH, and former head of the NMR Department at the Bayer Research Center (1988-1990), and has published books, reviews, and articles on the subject of NMR analysis. In the last few years, he has developed and published more than 50 NMR methods for analyzing food products, pharmaceuticals, and chemicals, and supported eight degree theses at HBRS and Spectral Service AG.

\section{Vanesa Y. Ixtaina studied Agrarian Science at Universidad} Nacional de La Plata (UNLP), Argentina, and obtained her Ph.D. at Facultad de Ciencias Exactas, UNLP, Argentina. She is a teacher of Plant Breeding and Analytical Chemistry at the Facultad de Ciencias Agrarias y Forestales (UNLP) and Professor of Food Chemistry in the post-grade Master in Food Technology and Hygiene (UNLP). Ixtaina is a researcher for the Consejo Nacional de Investigaciones Cientificas y Técnicas (CONICET, Argentina), and conducts her research activities at Centro de Investigación y Desarrollo en Criotecnología de Alimentos-CIDCA (CONICET-CIC-UNLP). She can be contacted at vanesaix@hotmail.com.
Mabel C. Tomás studied Chemistry at Universidad Nacional de Buenos Aires (UBA). She obtained her Ph.D. degree in Chemistry at Facultad de Ciencias Exactas, UNLP, Argentina. She is a researcher for Consejo Nacional de Investigaciones Cientificas y Técnicas (CONICET), Argentina, and conducts her research activities at Centro de Investigación y Desarrollo en Criotecnología de Alimentos-CIDCA (CONICET-CIC-UNLP). She is also Professor of Food Toxicology at the Facultad de Ciencias Exactas (UNLP) and in the post-grade Master in Food Technology and Hygiene (UNLP). She has edited one book, contributed various book chapters, and published more than 60 research works.

\section{References}

1. Rodea-González, D.A., J. Cruz-Olivares, A. RománGuerrero, M.E. Rodríguez-Huezo, E.J. Vernon-Carter, and C. Pérez-Alonso, Spray-dried encapsulation of chia essential oil (Salvia hispanica L.) in whey protein concentrate-polysaccharide matrices, J. Food Eng. 111: 102-109, 2012.

2. Ixtaina, V.Y., L.M. Julio, J.R. Wagner, J.R., S.M. Nolasco, S.M., and M.C. Tomás, Physicochemical characterization and stability of chia oil microencapsulated with sodium caseinate and lactose by spray-drying, Powder Technol. 271: 26-34, 2015.

3. Escalona-García, L.A., R. Pedroza-Islas, R. Natividad, M.E. Rodríguez-Huezo, H. Carrillo-Navas, and C. Perez-Alonso, Oxidation kinetics and thermodynamic analysis of chia oil microencapsulated in a whey protein concentrate-polysaccharide matrix, J. Food Eng. 175: 93-103, 2016.

4. Rodríguez, E.S., L.M. Julio, C. Henning, B.W. Diehl, M.C. Tomás, and V.Y. Ixtaina, Effect of natural antioxidants on the physicochemical properties and stability of freeze-dried microencapsulated chia seed oil, J. Sci. Food Agric. 99: 1682-1690, 2019.

5. Copado, C.N., B.W. Diehl, V.Y. Ixtaina, and M.C. Tomás, Application of Maillard reaction products on chia seed oil microcapsules with different core/wall ratios, LWT-Food Sci. Technol. 86: 408-417, 2017.

6. Augustin, M.A., L. Sanguansri, and O. Bode, Maillard reaction products as encapsulants for fish oil powders, J. Food Sci. 71: E25-E32, 2006.

7. Kagami, Y., S. Sugimura, N. Fujishima, K. Matsuda, T. Kometani, and Y. Matsumura, Oxidative stability, structure, and physical characteristics of microcapsules formed by spray drying of fish oil with protein and dextrin wall materials, J. Food Sci. 68: 2248-2255, 2003. 